\title{
Regionalisation and Its Impact on Quality Assurance in Higher Education
}

\author{
Ephraim Mhlanga \\ South African Institute for Distance Education, Johannesburg, South Africa \\ Email: ephraimm@saide.org.za
}

Received July 23 ${ }^{\text {rd }}, 2012$; revised August $24^{\text {th }}, 2012$; accepted September $10^{\text {th }}, 2012$

\begin{abstract}
In many parts of the world, higher education is still predominantly shaped at national level, and tends not only to reflect but also to underscore the specific traditions and circumstances of individual countries (Enders, 2002: p. 1). As a result, it has been mainly assessed in the context of national systems with very little attention being paid to its international dimension. In Southern Africa, this trend has largely been due to the nature of relationship that prevails between higher education and the nation state. This trend has started changing as globalisation and internationalisation factors exert more and more influence on the shaping of the institution of a university. This article argues that in Southern Africa, globalisation manifests itself through regionalisation, a process that has ushered in standardisation of quality assurance systems; a new managerialism in the management of higher education institutions; marketisation and commodification of knowledge; changing forms of state-university relationships; greater emphasis on efficiency, cost saving and income-generating discourse; the forging of university-private sector partnerships; and increasing staff and student mobility in the region and on the continent. The article pursues these themes and shows how they impact on the quality of delivery of three case universities in Southern Africa.
\end{abstract}

Keywords: Quality Assurance; Higher Education; Regionalisation; Southern Africa

\section{Introduction}

In many parts of the world, higher education is still predominantly shaped at national level, and tends not only to reflect but also to underscore the specific traditions and circumstances of individual countries (Enders, 2002: p. 1). As a result, it has been mainly assessed in the context of national systems with very little attention being paid to its international dimension. In Southern Africa, this trend has largely been due to the strong relationship that prevails between higher education and the nation state. Generally, higher education has long been almost wholly publicly funded and therefore strictly controlled by the state. Under these circumstances, quality assurance mainly served as a form of public accountability and the nation state steered the system as the sole player with a significant stake in higher education. However, this trend has started to change and the predominance of the nation state as the main determinant of the character of universities is now heavily challenged. Thus, although state influence is still dominant in most universities in Southern Africa, the higher education system today is characterised by de-nationalisation, a process where states are losing their monopoly on the control of university institutions while at the same time the systems are gradually being shaped by factors beyond their national borders. Significant among these external factors is the influence of globalisation and internationalisation forces on local higher education systems and on quality assurance in particular.

Based on a study that was conducted in three public universities (for which pseudo names will be used) in three countries in the Southern African Development Community (SADC) region, this paper argues that regionalization takes the following forms:
Within the SADC region and indeed in sub-Saharan Africa, regionalisation ushers in 1) standardisation of quality assurance systems; 2) a new managerialism in the management of higher education institutions; 3) marketisation and commodification of knowledge; 4) changing forms of state-university relationships; 5) greater emphasis on efficiency, cost saving and incomegenerating discourse; 6) the forging of university-private sector partnerships; and 7) increasing staff and student mobility in the region and on the continent. The seven factors above provide a sound theoretical framework for analysing how the process of regionalisation is shaping university practice in Southern Africa.

This paper pursues these themes and shows how they are influencing the operations of the three case institutions. It also shows the impact of these thematic factors on quality assurance. A pertinent question which arises is whether these practices have sufficient potential to enhance the quality of higher education in the region. This paper attempts to address this question, with specific reference to the case institutions.

Within Southern Africa, globalisation is assuming the form of regionalisation, a process that involves the creation of a common space in the various aspects of social and economic development of the countries within the region. As in the European Union, the process is characterised by the adoption of common policies on matters of education, trade, migration and general development. There is increasing realisation globally of the importance of close co-operation between countries through sharing resources and technologies, addressing common problems and facilitating the free movement of people (COMEDAF III Report, 2007). The key advantage of creating such regional blocs lies in the benefits individual countries enjoy in con- 
fronting problems as a group rather than as individuals, and in building on each other's synergies in the process of development. Member countries support each other in the process of economic development by concentrating on different niche areas.

\section{Regionalisation and Higher Education in Southern Africa}

Loosely defined, regionalisation refers to the grouping of nations within a common geographical location in order to strengthen cooperation and sharing as a strategy for achieving development. Such groupings are motivated by physical and cultural proximity as well as by common challenges faced. The process of regionalisation gives institutions an international character.

\section{The Regionalisation Project}

In Southern Africa the project of regionalisation has undergone several metamorphoses. Starting as an apartheid project during colonialism, this political project was aimed at integrating the region into a wider Southern African economy. This was to be achieved by creating a constellation of states within the region that would promote, support and consolidate colonial interests. As more states became politically independent within the region, they reconceptualised the concept, through the formation of the Southern African Development Co-ordination Committee (SADCC), into an emancipatory strategy. The regional body was meant to facilitate collaboration and co-ordination of activities among the member states. Such collaboration was extended beyond political frontiers to include economic and social dimensions of development. In order to enhance development, the regional body identified niche areas for member countries, and co-ordinated development in those areas for the benefit of the entire region. These areas included, among others, transport networks, regional food security, mining and fisheries, tourism, and the development of energy resources. Thus, efforts were made to identify areas of economic strength, including the natural resource endowments of each member country, which were to be developed for the benefit of the region.

SADCC evolved into the Southern African Development Community (SADC), a body that is increasingly becoming an expression of globalisation, much like the European Union. There is increasing awareness that for the region to develop into a knowledge society and catch up with other regions, human resource capacity is a key prerequisite. Thus, various strategies for enhancing higher education in the member countries are being mooted. Amongst other measures, these strategies include harmonising and integrating higher education national systems with a view to forming a regional higher education space that is competitive in terms of scholarship and efficient in meeting the human resource needs of the region.

The SADC Protocol on Education and Training is one instrument meant to achieve such harmonisation of the system. Article Seven of this Protocol deals with co-operation in higher education and training and clarifies some of the key areas of harmonisation. The major aim of the Protocol is "to progressively achieve equivalence, harmonisation and eventual standardisation of the education and training systems in the region" (COMEDAF III Report, 2007). The SADC Technical Committee on Certification and Accreditation (TCCA) was established in 1997 with a specific mandate to develop and recommend policy guidelines, instruments, structures, and procedures that would eventually facilitate equating, harmonising, and standardisation of accreditation and certification of qualifications in the SADC region. To achieve this mission, the TCCA set the following objectives:

- to facilitate the development and implementation of national qualifications frameworks;

- to facilitate harmonisation of national qualifications frameworks into the development of a regional qualifications framework;

- to strengthen national assessment, quality assurance and accreditation structures, systems and procedures, and

- to facilitate the development of credit transfer systems. ((COMEDAF III Report, 2007).

Clearly, one of the focus areas of efforts at enhancing regional integration of higher education amongst the SADC countries is by improving the quality assurance systems of institutions. Among other tasks, the TCCA undertakes studies and analyses of issues of accreditation and recognition, which provide a basis for making recommendations that lead to comparability of criteria of evaluations and recognition of degrees within the region. The SADC TCCA has reportedly initiated the process of establishing a regional qualifications framework known as the Southern African Development Community Qualifications Framework (SADCQF). In 2006, the TCCA produced a Draft Concept Paper on the SADC Qualifications Framework, in which it proposed the establishment of a SADC Qualifications Agency. On the recommendations of the Ministers responsible for higher education in the SADC member countries, the TCCA should first focus on assisting countries to strengthen their quality assurance systems before the development of national and regional qualifications frameworks. The activities of the TCCA are clear demonstration of the trend towards greater harmonisation of higher education offerings, standardisation of quality assurance systems and the creation of a common regional higher education space. There is however, greater realisation that progress in the SADC region cannot be seen in isolation from global developments, and that member institutions will be very much influenced by international trends in their quality assurance practices.

Beyond the SADC region, regionalisation on the continent is further driven through the formation of bodies like the New Partnership for Africa's Development (NEPAD), the African Council for Distance Education (ACDE), the Association of African Universities (AAU), the Association for the Development of Education in Africa (ADEA), the Southern African Regional Universities Association (SARUA) and the African Virtual University (AVU). All these organisations seek common strategies towards addressing educational problems in Africa and in the Southern African region, particularly in addressing the pressing challenges of access, equity and quality assurance.

A significant result of regional integration in higher education is the enhancement of both student and staff mobility across institutions within the region and on the continent in general. There is also harmonisation of policy and guidelines for quality assurance and the evaluation of qualifications across institutions in order to facilitate equivalency and comparability. Such comparability further enhances student movement and credit transfer across country institutions. 


\section{Standardisation of Systems and Strategies}

Standardisation of higher education and of quality assurance systems in particular, is explicitly expressed through the activities of several bodies on the continent and in the Southern African region in particular. The Arusha Convention of December 1982, which was subsequently revised in 2002 in Cape Town and in Dakar in 2003, is one such initiative. This Convention pushes for the recognition of certain studies, certificates, diplomas, degrees and other academic qualifications in higher education in African countries. Underlying this move is the principle of harmonisation and portability of qualifications on the continent.

The African Union (AU) is developing a strategy for harmonising higher education programmes, and at the core of this initiative is the development of criteria for harmonising qualifications across countries. There is talk of joint training and joint offering of certain degree programmes in order to provide skills that are considered key to economic development on the continent. The African Council for Distance Education has identified as its priority area the establishment of Pan African Standards and of a regional quality assurance and accreditation body for distance education-the African Council for Distance Education Quality Assurance and Accreditation Agency (ACDE-QAAA). This continental quality assurance and accreditation agency was formed in 2010 and is currently developing quality assurance criteria for use by higher education ODL providers on the continent. Amongst other support mechanisms, the ACDE-QAAA is also developing a manual for good practice in ODL as a way of enhancing the quality of open and distance education in higher education on the continent. Thus, benchmarking of standards in programme offerings becomes a regional rather than an institutional concern.

The Association of African Universities is poised to raise standards of higher education in African countries, primarily by building capacity in the area of quality assurance. In Southern Africa, the promotion of national and regional qualifications frameworks has been on the agenda for quite some time, again in order to facilitate mobility and portability of qualifications across countries. The aspired consequences of all the abovecited initiatives by various organisations are regional integration through increased regional student and staff mobility; increased sharing of information, intellectual resources and research; strengthening African expertise to avoid over-reliance on skills from elsewhere; promotion of greater networking within the region; and the creation of a common African higher education and research space. These aspects are considered core in so far as the quality enhancement of higher education provision in Africa is concerned.

Regionalisation has an indirect but very profound influence on institutional quality assurance. Apart from giving higher education a transnational character, today's market-driven regionalisation fosters similarities that are related to the "consolidation of international (and regional) epistemic communities that seek common responses to common problems" (Torres \& Schugurensky, 2002: p. 43). The dynamics of regionalisation in Southern Africa have a significant impact on the perceptions of what constitutes valuable knowledge and quality degrees, and hence influence how institutions proceed to quality assure their offerings. At the same time, national quality assurance agencies try to align their quality assurance systems with regional quality assurance frameworks and with the ideals of international quality assurance agencies. At Universities B and $\mathrm{C}$, for instance, it was evident that in developing institutional quality assurance systems there was extensive consultation with international and regional experts, sometimes at the expense of local stakeholders. Although there was no evidence of similar consultations at University A, the literature shows that international consultation was quite extensive in developing quality assurance policy at national level in South Africa (Kraak, 2004). Because of regionalised markets, "ways are needed to provide, internationally, information about the nature, level, and quality of education” (Woodhoues, 2001: p. 1) of any university institution that claims space on the regional higher education market. Within the region, institutions closely follow market trends and try to align their degrees and their research programmes with the demands and needs of the ever-changing and expanding regional market. A typical example of this is the increasing recruitment of students and academic staff by South African universities from the rest of the continent. According to a survey conducted at Wits in 2004, 9 percent of the surveyed students came from the SADC countries while 8 percent came from the rest of the African continent (Cross, Sehoole, Mhlanga, Bayers-Ameguide, Inglis, \& Koen, 2004). The vision of the University of South Africa (UNISA), for instance, places the institution as an African university that is poised to serve South Africa and the African continent. Due to regionalisation, universities within the region find themselves in a new information age in which society, the economy and knowledge have become part of an irresistible regional environment, and therefore are forced to conform to regional trends, consciously or unconsciously. This trend is greatly enhanced through the growing awareness by universities of international and regional cooperation, collaboration and competition in the globalised higher education market (Enders, 2002).

\section{A New Managerialism}

In most regional institutions, including the three case universities for this study, an emerging trend is that managers have assumed greater importance and enjoy heftier benefits than academic professionals. Greater emphasis is placed on "hard" approaches to management in order to achieve efficiency. As Cloete and colleagues confirm from their study of the South African higher education system, many vice-chancellors believe that the biggest challenge facing their institutions has shifted away from achieving the national goals of equity, democracy and relevance to one of safeguarding the "bottom line" (Cloete, Bunting, \& Kulati, 2000, cited in Cloete, Kulati, \& Phala, (eds.)). The same authors note that at most of the South African universities they studied, the struggle to stay solvent had become the new battlefront (Ibid). In order to achieve such solvency, institutions have resorted to tight management systems that are characterised by an entrepreneurial ethos. The three case universities, like business enterprises, now engage managers at every level of the system and these managers emphasise performativity - the capacity to deliver outputs at the lowest possible cost. New managerialism manifests itself in the increasing levels of accountability on the part of institutions and the individuals therein, and in the growth of an audit culture within the institutions. There is an apparent tendency for quality assurance policies for these institutions to privilege managerial values more than epistemic ends. As is shown in the following section, marketisation and commodification of knowl- 
edge have profoundly influenced enrolments for the three case universities, the forms of knowledge they privilege, and the type of research they engage in.

\section{Marketisation and Commodification of Knowledge}

While the process of globalisation is not new, what seems to be novel about it, especially within the Southern African context, is the degree of expansion in trade and transfer of capital, labour mobility, production, consumption, information and technology which, together, are ushering in significant changes in lifestyles, working patterns, how nations relate to one another within the region, and how institutions deliver their programmes and set their research agenda. Like anywhere else in the world, universities within the region are listening more to the voice of the market than ever before. Market-induced processes, driven mainly by market expansion, are informing what counts as valid knowledge and what disciplines to prioritise. Regionalisation is enhancing transnational business activities that thrive on selling the culture-ideology of consumerism. The expansion of South African companies and businesses to other countries within the region and indeed on the continent is a typical example of such market expansion. Mobile communication, mining, finance and retail companies are fast penetrating the regional markets. The same trend is noticeable in the field of higher education, where South African universities are recruiting more and more students and academic staff from the region. The ideology of consumerism privileges the perpetual expansion and growth of the regional market. Thus today's market-driven globalization, with its push for commercial interests that protect profits rather than people, is an unstoppable process on a world (and indeed regional) scale (Yang, 2003: p. 272).

The market discourse has entrenched itself quite significantly in higher education and has influenced new ways of redefining the role of the African university and the clients that it serves. All the three universities studied advertise conventional programmes as well as innovative short courses offered to employees in various fields, the latter mostly on a part-time basis. Such short courses are meant to attract more revenue for the institutions. They also run university enterprises, forge partnerships with the private sector, and engage in a number of income-generating activities. There is rapid shifting of these universities from being public institutions that serve public interests to being entrepreneurial enterprises that operate as business entities that view students as consumers and that survive on values of competition and efficiency. This shift is likely to exert greater influence on what universities prioritise and how they do their business. As some scholars in higher education studies argue, the notion of higher educational serving a form of collective public good is fast disappearing; instead participation in tertiary education is now regarded as a form of private investment (Sosteric, Gismondi, \& Ratkovic, 1998). This is particularly noticeable at University A and University C. This thinking explains why students (consumers) at University A are required to shoulder the bulk of the increasing cost of higher education. It also explains why organisations like the World Bank have in the past recommended less public investment in higher education than in basic and secondary education. Institutional operations and policy decisions are informed more by corporate values than by epistemic ones.

The desire to do more with less (e.g. upping student-lecturer ratios, increasing teaching hours for staff, making staff do with minimum of resources needed for effective teaching and research) was one of the major identified threats to quality delivery in the three universities studied. Staff in the three institutions was very concerned about the practice of basing planning on the economic rationale.

There is evidently the generic problem of large class sizes in the studied universities. At the University B, most staff reported that they handle classes that are generally too big for the available lecture rooms in the university. In some cases, students spill out of the small rooms during lectures and this has a demotivating effect on the students. Most departments reported undergraduate class sizes of between 100 and 300 students. The general view of staff at University B is that class size is an essential variable militating against quality teaching and learning at the university and requires urgent attention if the quality assurance policy is to yield the desired results. At University A, 22.5 percent of the surveyed staff taught classes that were 150 students or more, while 15 percent taught classes that had more than 200 students.

The literature shows that class size has an effect on the quality of learning that takes place in a class:

It is generally agreed that class size has profound effect on the quality of learning that takes place in a class. Class size affects not only the extent of one-on-one interaction that takes place during learning, but also enhances individual support form the teacher.

The tendency in the studied universities and indeed in many other universities within the region, to handle too many students using minimum resources and to engage academic staff at unattractively low salaries leads to the creation of Fordist-style degree mills (Noble, 1997, cited in Sosteric, et al., 1998). Postmodern theorists call it "performativity" that is, "the capacity to deliver outputs at the lowest cost which replaces truth as the yardstick of knowledge" (Crook, et al., \& Smith, 1997: p. 323). This practice defeats the whole purpose of achieving academic excellence by universities as it constrains the effective implementation of the quality assurance policies in the case universities.

Commercialisation of research has now seen the privileging of applied research at the expense of basic research. In the South African context, for instance, patterns in research and publishing show an alarming tendency to "follow the money" (Ibid).

In all three universities studied, curriculum relevance is viewed in terms of knowledge application to the world of work, and the market is exerting profound influence on curriculum reforms. At University A for instance, the Faculty of Humanities closed down some of the departments that were considered to be out of touch with market trends, like Classics, Religious Studies and Afrikaans. Other disciplines like History are equally threatened with closure due to the limited number of students who opt for them. At the same time, new study areas are being introduced because they are considered to be relevant to current market trends, and for this reason they attract large numbers of students and significant revenue. Examples of such areas are Work and Labour in the Global Economy (a sociology field) and Issues in South African News Media. All these curriculum trends are influenced by market ideology. Decisions as to whether courses will or will not be delivered are measured by their financial viability and not only by their long-term intellectual contribution to the project within the unit (Johnson, 2005). The notion of profit centres forms the hallmark of the 
functioning of academic centres, and institutions are run on business/corporate lines, including the use of strategic plans.

The practice of university curricula following market trends rather than knowledge for its own sake was not only peculiar to University A; it was also noted at the other two case study universities. The literature shows that this is a common trend worldwide in higher education systems and is an integral aspect of globalisation. As Carnoy would argue, globalisation enters the field of education on an ideological horse (Carnoy, 1999: p. 59). Institutions continually scan the market, and their success is determined by their ability to adjust and align themselves with the needs and demands of the market. It is the neo-liberal ideology that ushered in economic reform policies that promote massive privatisation and decline in public spending, removal of trade barriers and promotion of export orientations, deregulation of markets and reduction of state intervention in the economy. All these aspects are characteristic of higher education in the Southern African region. Such policies, which have also been strongly supported by the International Monetary Fund (IMF) and the World Bank (themselves peddlers of the globalisation process) in developing countries, have had the overall impact of increasing corporate culture in the operations of universities, institutions that hitherto functioned primarily for the public good.

In higher education, it is clear that globalisation has changed the discourse of rights into an economic discourse of investment, where decisions to invest are determined purely by the perceived social returns of such investments. Such rationale is not consistent with the equity values espoused by most Southern African countries. It also falls far short of providing a conducive funding framework for institutions to manage effective quality assurance systems.

\section{State-Institution Relationships within a Regionalised Market}

Regionalisation and internationalisation forces have also influenced the changing patterns of state-institution relationships. The first effect of regionalisation was the ushering in of new international reform ideologies that fundamentally challenged the notion of institutional self-steering in higher education (Maasen \& Cloete, 2002: p. 16). Regionalisation has led to the broadening of the role of higher education policy to embrace economic growth, the promotion of the knowledge economy, internationalisation and trade (Carnoy, 1999: p. 59). The assumption that universities and colleges should be left to steer themselves has been challenged. Instead, the new thinking is that universities should be externally steered, subjected to market forces, audited through formal evaluation, accountable for their performance, and run by professional leaders and managers rather than academics (Tertiary Education Policy for Botswana). This reform thinking is characterized by what scholars like Neave call "the rise of the evaluative state" (Neave, 1998), a situation where universities are externally controlled and their activities are subjected to regular evaluation by the state. The rationale behind this thinking is that universities in the region, very much unlike in the developed world, are key instruments for inducing social and economic development, and hence the importance of state steering in order to align their activities with broader national and regional development plans. Thus, the impact of international reform ideologies has been the rejuvenation of state interest in the running of university affairs.
This thinking has informed the relationship between the state and universities in the Southern African region. Whilst such steering is positive, there is the danger of coercing universities to follow a narrow knowledge agenda.

Another significant effect of regionalisation has stemmed mainly from the international connectedness that has been brought about through the Internet, mobile telephony and intensifying patterns of travel (Neave, 1988: p. 17). In recent years, such forces have also been felt through the General Agreement on Trade in Services (GATS) under the auspices of the World Trade Organization (WTO). Such agreements as GATS have accelerated the influx of private and foreign providers of university education where domestic capacity is inadequate, and this has mainly been in developing countries. Transnational provision of higher education has emerged as big business for universities in the developed world, especially in Australia, the United Kingdom (UK) and the United States of America (USA). Although South Africa and Botswana have not signed to the GATS, the phenomenon of foreign providers of higher education was noted in both countries; it is one of the factors influencing how governments position themselves in relation to the national higher education institutions. This development, which has been largely enhanced by the liberalisation of the higher education market, takes various forms, like recruitment of international students, establishment of campuses abroad, franchise provision and online learning. There is great concern by some developing states that liberalisation of higher education may not only hamper the development of institutions in the developing countries through stiff competition, but also compromises on quality of programme offerings (Knight, 2003: p. 5). As a result of these concerns, transnational provision of higher education has further awakened the interest of states in the regulation of domestic higher education policies, particularly in the area of quality assurance. Such regulation has been done in the name of protecting local consumers against provision of poor-quality university education by unscrupulous foreign and private providers who seek nothing more than profits. State regulation has also been aimed at making institutions more competitive by making them international in terms of their curricula, by enrolling increasing numbers of international students and by recruiting international staff. Positive effects of state regulation were identified at the University A, where, as highlighted above, both international students and staff were very significant aspects of the institution's demographics. To some extent, University B also showed some of these international features, particularly with regard to staffing.

\section{Efficiency, Cost Saving and Income Generation}

An important impact of regional integration is the shift of policies in higher institutions to promote economic efficiency through the liberalization and deregulation of markets. The implication of deregulating national markets is the emergence and growth of a regional integrated market that masks the long tradition of local markets and in the process forces nation states to retreat in terms of shaping economic activities within their countries. Integrated markets, especially in higher education, do not only call for an interstate (or global) regulating system, they also raise questions regarding the relative benefits that accrue to individual countries, given their different competitive capacities in such integrated regional markets. Thus, activities of institutions are left to be shaped mainly by market forces. Institutions 
need to raise enough revenue in order to survive, and to do so they have to be competitive and innovative enough to attract sufficient clients from the market, which is now defined in regional rather than in national terms. In a market situation, those with stable leadership, with ability to be responsive to market demands, and those that have the skills and resources to move in new directions, will be at an advantage (Ibid). Rich institutions stand to benefit as they have the capacity to move quickly and take advantage of the expanded market, drawing students and staff from countries where there are weak institutions that have shaky quality assurance systems. At the same time, the presence of foreign providers in the region obviously introduces competition for the local, poorer universities.

This jungle situation of survival of the fittest is certainly in favour of institutions that have an upper hand in terms of quality delivery. Thus, regional integration is a significant phenomenon of globalisation that is in favour of allowing market forces to determine what institutions can offer and with what amount of success. Rui Yang aptly describes the gloomy side of market-induced policies and economic systems:

Arguably, the market has gone too far in dominating social and political outcomes. The opportunities and rewards of globalization spread unequally and inequitably—concentrating power and wealth in a select group of people, nations and corporations, while marginalizing others. When the profit motives of market players are unconstrained, they challenge people's ethics and sacrifice respect for justice and human rights. It is just here where the market falls short. It places the whims of the rich over the most elementary necessities of the poor. The market cannot safeguard the needs of those without money, which is why so many people die every day within sight of global abundance. In this sense, the market is deaf and blind. It responds only with the sensory equipment that can detect money (Yang, 2003: p. 272).

In a situation where the logic of the market determines service provision and patterns of consumption, the role of the state in protecting the weak against being down-trodden by the more powerful is severely eroded. The state's prime role of protecting the rights of all citizens in the higher education system is undermined. As already mentioned above with regard to the provision and governance of university education, globalisation has resulted in a shift from the logic of rights to a logic premised on economic convenience. Market-driven higher education systems inevitably call for a different kind of relationship to be established between higher education institutions and the state. This repositioning of the state has many implications regarding state monitoring of the quality provision of these institutions and aligning higher education with overall national development goals. Regional countries ought to analyse the direct implications of globalisation on higher education in terms of various dimensions like staffing, changing forms of knowledge and the nature of work in the academy, and relations with other social agents. Similar concerns need to be raised at regional level regarding moves to open up the regional higher education market to transnational providers.

There are particular symptoms of regionalisation that have bearing on quality assurance which can be identified in the studied institutions. These relate to performativity, professionalisation of degrees, and standardisation of degrees and qualifications in order to facilitate labor mobility and credit transfer. Because of the need for universities to account to external stakeholders like the state, management emphasises measurable aspects of staff performance and by so doing shifts the academic staff from their traditional roles and interests to those aligned to the organisation (Johnson, 2005: p. 210). As alluded to earlier on, the concern with performativity does not necessarily focus on epistemic issues that improve the performance of universities as academic institutions.

\section{Partnerships}

Marketisation of higher education is characterised by closer partnerships between universities and outside clients and other knowledge producers, and an increasing burden on faculty to access external sources of funding (Subotzky, 2006: p. 2). The success of an institution is measured in terms of its ability to forge such partnerships with strategic partners and to maximise revenue generation. This practice has had profound influence on the way the studied institutions perceive knowledge and the resultant restructuring of degree programmes in order to meet the immediate needs of the market. In all the three universities used in this study, the trend to professionalise degree programmes and commodify knowledge was very distinct. Institutions run many new short courses that are offered in order to cater for the immediate needs of particular professions, especially in the Business and Education schools and faculties. In all three universities, some of these courses are run in the evenings and during weekends in order to allow working clients an opportunity to attend. This tendency to professionalise degree programmes is clearly a market-driven innovation which privileges mode 2 forms of knowledge at the expense of mode 1 . The important point to note here is that customisation of university offerings for particular professions and other immediate business client needs has undoubtedly resulted in considerable influence being exerted on institutions in terms of their curricular reforms and the way they benchmark their quality in those programmes. It was also worth noting that such outside business partners influence, in very significant ways, how quality should be assured, not only in the academic programmes offered but also in the form of research that is undertaken in some of the studied universities. In all three contexts of this study, particularly in South Africa, institutions have aligned their research with the national and regional market as well as with national development goals. There is a dramatic shift away from basic toward applied research—a 25 percent shift over a five-year period is reported in South Africa (Bawa and Mouton, 2002, cited in Muller, 2005: p. 96). One interviewed academic at Wits confirmed the influence of external factors like professional organisations and the market on curricula:

We have the generic quality assurance policy by the university, but within the faculty our programmes are accredited according to certain professional requirements. There are professional organisations that make an input into our programmes and they accredit those programmes.

Our programmes are developed around certain professions internationally and locally. These include the Royal Chartered Institute of Quantity Surveyors, the South African Council of the Built Environment. These organisations have certain demands on our programmes. Their demands are higher than what the Higher Education Council requires. ${ }^{1}$

Thus, the perception of quality and the way it is assured was identified as a product of the concerted efforts of the universi-

\footnotetext{
${ }^{1}$ Interview with the quality assurance coordinator in the Faculty of Engineering
} University A, 7 April 2005. 
ties and their outside partnerships. At University A this was mainly conspicuous in the fields of Engineering and Business Studies. At University $\mathrm{C}$ the practice was quite prevalent in Agriculture, Commerce and Business, and Education. At University $B$ the trend was noticeable in the Faculties of Engineering and Business Studies as well as in the Nursing Science degrees.

The practice where external stakeholders, especially professional organisations, have influence in quality assuring university activities is becoming a global trend. Motivated by the increasing international mobility of professionals and facilitated by regional and global trade agreements which concern the international trade in professional services, these professional organisations initiate far-reaching agreements on mutual recognition of professional qualifications and on international quality standards, and actively support the development of international accreditation practices (Van der Wende, n.d.: p. 3). As exemplified by the above interview citations and examples, this is quite a significant trend influencing quality assurance of particular disciplines in the studied universities.

It was also apparent in this study that, due to the role of external partners with a stake in university business, a new dimension of multiple accreditations could become an important component of quality assurance of programmes in universities. The impact of globalisation in the studied cases is thus characterised by epistemological and organisational changes towards applications-driven or strategic forms of knowledge production and dissemination (Subotzky, 2006: p. 2).

\section{Student and Labour Mobility}

Regionalised markets operate alongside the phenomenon of a regional economy, which survives largely on mobility of capital and labour across national boundaries. Within the Southern African region, this "regionality" necessitates the prevalence of labour mobility across geographical boundaries and across national economies. Countries within the same geographical and political regions are increasingly recognising the need to collaborate in order to facilitate mobility of students and skilled labour in an orderly manner (The Statesman, 2007: p. 4). There is increasing relaxation of migration regulations among countries within the Southern African region, a development that makes cross-border travel easy for students and academic staff. For this to happen more smoothly, there are moves within the region to standardise qualifications from universities and other tertiary institutions. This encourages harmonisation of study programmes, articulation of qualifications and cross-transfer of credits. Thus, one of the effects of regional integrated higher education systems is to maximise standardisation in particular disciplines in order to facilitate labour mobility as well as student exchange. In line with this trend, institutions are aligning their quality assurance arrangements with those of regional and international agencies; hence the increasing discourses of internationalisation (and regionalisation) of quality assurance of university education (Van der Wende, n.d.). Within Southern Africa, this process is augmented by efforts at establishing a regional quality assurance agency that enhances quality among the regional institutions. Such an agency also ensures that higher education institutions stretch themselves up to quality levels that make them competitive at international level. In the region, this is partly being achieved by encouraging the formation of national councils of higher education which, in turn, affiliate to the regional body. National Councils of Higher Education were a common phenomenon in all the three countries studied, and one of their key functions is the regulation of higher education through quality assurance.

Given the broader discourse of international exchange and co-operation emphasised by nation states, international bodies and business today, the advent of the "universalism of learning" and "the universal-university world" (De Wit, 2000: p. 1) becomes inevitable. If regionalisation is to promote quality delivery in the studied institutions, strategies institutions adopt to achieve this goal become critical. Development of quality delivery through partnerships is a matter of institutional strategy:

But too often such cooperation agreements are merely expressions of academic good will or the product of transient opportunities. Their numbers are generally more impressive than the quality of the contributions they make. What most African universities need are partnerships that are few in number, strategically chosen, and equitable in the benefits provided to each partner. Such partnerships hold the potential to make an institution stronger, more competitive, and more relevant. To achieve this, these partnerships must emerge from an institution's strategic planning process (The Statesman, 2007: p. 7).

The narrow approach common in the institutions, where regionalisation is taken to be one or two activities-like staff mobility, multicultural education, area studies, study abroad or the establishment of an international office-certainly needs to be broadened so that it constitutes a comprehensive and more holistic approach that permeates every facet of university operations and that has an impact on the experiences of students. This broader and more integrated approach stands more chances of impacting more positively on the quality performance of the universities; this was clearly absent in the studied universities.

\section{Conclusion}

This paper showed how globalisation and internationalisation influence higher education reforms in general and quality assurance in particular in the Southern African context. It presented globalisation and internationalisation within the context of regionalisation of higher education in the Sub-Saharan region and tried to show how the latter process is transforming national economies into an integrated regional economy, and national higher education systems into interconnected entities operating in resonance with each other. In the social sphere regionalisation has the effect of intensifying social relations at a distance, making it imperative for what happens in one country to resonate throughout the entire region and to affect what happens everywhere else in the region. The paper showed deregulation of markets as one of the major effects of regionalisation, which has had the effect of blurring national boundaries in terms of both provision and consumption of higher education services. The overall impact has been the invasion of the system by a market ideology which emphasises competition, economic efficiency and consumption. Market discourses have permeated higher education and are noticeably influencing the options of the studied universities. Thus, there is competition by universities for the best clients in the regional market-a process that has been exacerbated by the advent of private providers of higher education, including those from the most advantageously placed institutions overseas. At the same time, students' choices have been broadened as they seek relevant degrees that are of international standard. 
As a way of responding to the emergence of a global economy, the case institutions are increasingly placing more emphasis on regionalisation-a process that involves cultural integration in teaching and learning as well as the research activities of a university. Among other motives, regionalisation is seen as a way of enhancing the quality offerings of these universities, through providing an international experience to staff and students, through mutual exchange of ideas and through regional and international co-operation and information sharing between agencies and institutions responsible for quality assurance. University education is being extended beyond the local in terms of curricular restructuring, so is the benchmarking of the practices and standards. The pressures of globalisation and internationalisation have extended the scope of the market, the student and staff catchment area, needs and priorities to be met in terms of research concerns, and programmes offered are well beyond national and regional boundaries. A trend that is emerging in the case institutions, perhaps just like elsewhere, is the move towards benchmarking quality assurance in accordance with regional and international standards, irrespective of the level of development of the institution. This is done mainly by aligning institutional policies and practices with regional and international trends and norms, in spite of the constraining local imperatives, and by intensifying peer review processes as a key aspect of quality assurance. This need is evidenced by the extensive consultations made with outside experts on quality assurance as well as by the affiliation of institutions to regional and international quality assurance agencies like the Association of African Universities, the Southern African Regional Universities Association, and the International Network of Quality Assurance Agencies in Higher Education.

Thus, this paper shows that while quality assurance policies of these developing case institutions are influenced by local imperatives, they are increasingly being influenced by regional dictates. As Enders rightly argues, internationalisation and globalisation became key themes in the 1990s, both in higher education policy debates and in research on higher education (Yang, 2003: p. 272). Universities are both subjects as well as objects of internationalisation and globalisation; they are affected by and at the same time influence these processes. Quality assurance policies and practices in the studied institutions are no exception in this regard.

\section{REFERENCES}

Carnoy, M. (1999). Globalization and educational reform: What planners need to know. Paris: UNESCO.

Cross, M., Sehoole, T., Mhlanga, E., Bayers-Ameguide, P., Inglis, J., \& Koen, S. (2004). University experience in the 21st century: Perceptions of global and local exposure at the University of the Witwatersrand, unpublished research report. Johannesburg: University of the Witwatersrand.

De Wit, H. (2000). Rationales for internationalisation of higher education. URL (last checked 5 May 2006).

http://www.ipv.pt/millenium/wit11.htm.

Delucchi, M., \& Smith, W. L. (1997). A postmodern explanation of student consumerism in higher education. Teaching Sociology, 24, 322-327. doi:10.2307/1319301

Enders, J. (2002). Higher education, internationalisation, and the nation state: Recent developments and challenges to governance theory. A paper prepared for the CHER conference, Vienna, Austria.

Harmonization of higher education programmes in Africa: Opportunities and challenges. (2007). A report of the third ordinary session of the conference of ministers of education of the African Union. Johannesburg, South Africa.

Johnson, B. (2005). Towards post-managerialism in higher education: The case of management change at the University of the Witwatersrand. Unpublished Doctoral Thesis, Johannesburg: University of the Witwatersrand Library.

Knight, J. (2003). Trade in Higher Education Services: The Implications of GATS. Kagisano, 3.

Kraak, A. (2004). Discursive tensions in South African Higher Education, 1990 to 2002. Journal of Studies in International Education, 8, 244-281. doi:10.1177/1028315304265337

Maasen, P., \& Cloete, N. (2002). Global reform trends in higher education. In Cloete, N. et al. (Eds.), Transformation in higher education: Global pressures and local realities in south africa (pp. 13-57). Kaapstad: Cape Town.

Muller, J. (2005). The world is not enough: Knowledge in question. South African Journal for Higher Education, 19, 89-103. doi:10.4314/sajhe.v19i3.25506

Neave, G. (1988). The Evaluative State Reconsidered. European Journal of Education, 33, 206-283.

Sosteric, M., Gismondi, M., \& Ratkovic, G. (1998). The University, accountability, and market discipline in the late 1990s. Electronic Journal of Sociology, CAAP.

http://www.sociology.org/content/vol003.003/sosteric.html

Subotzky, G. (2006). Globalisation and higher education. URL (last checked 18 May 2006). http://firgoa.usc.es/drupal/node/26911

The Statesman (2007). Revisioning Africa's tertiary education in the transition to a knowledge economy. URL (last checked 5 September 2007). http://www.thestatesman.net

Torres, C. A., \& Schugurensky, D. (2002). The political economy of higher education in the era of neo-liberal globalisation: Latin America in comparative perspective. Higher Education, 43, 429-455. doi:10.1023/A:1015292413037

Van der Wende, M. (n.d.). Quality assurance in higher education and the link to internationalisation (1) Paper to be published by the OECD in a publication with the title: "Quality and the International Dimension in Higher Education Institutions”. URL (last checked 7 December 2005). http://www.ipv.pt/millenium/wende11.htm

Woodhoues, D. (2001). Globalisation: Implications for education and for quality. A paper presented at the AAIR Conference held at Rockhampton, Australia.

Yang, R. (2003). Globalization and higher education development: A critical analysis. International Review of Education, 49, 269-291. doi:10.1023/A:1025303303245 